\title{
Impact of physical exercises on immune function, bone mineral density, and quality of life in people living with HIV/AIDS: a systematic review with meta-analysis
}

Sam Chidi Ibeneme ${ }^{1,4,6^{*}}$ D, Franklin Onyedinma Irem', Nneka Ifeyinwa lloanusi ${ }^{2,4}$, Amarachi Destiny Ezuma ${ }^{3,4}$, Fortune Elochukwu Ezenwankwo', Philip Chinedu Okere ${ }^{2,4}$, Amaka Obiageli Nnamani ${ }^{2,4}$,

Salome Nwaelom Ezeofor ${ }^{2,4}$, Ngozi Regina Dim ${ }^{2,4}$ and Gerhard Fortwengel $\left.\right|^{5,6}$

\begin{abstract}
Background: Compromised immune function, associated with human immune deficiency virus(HIV) infection, is improved by antiretroviral therapy(ART) which also decreases bone mineral density(BMD), and possibly the quality of life(QoL). However, physical(aerobic/resistance) exercises, were reported to induce reverse effects in uninfected individuals and were appraised in the literature for evidence of similar benefits in people living with HIV/AIDS(PLWHA). The main study objective was to evaluate the impact of physical (aerobic and resistance) exercises on $C^{4+}$ count, BMD and QoL in PLWHA.

Methods: A systematic review was conducted using the Cochrane Collaboration protocol. Searching databases, up to June 2017, only randomized control trials investigating the effects of either aerobic, resistance or a combination of both exercise types with a control/other intervention(s) for a period of at least 4 weeks among adults living with HIV, were included. Two independent reviewers determined the eligibility of the studies. Data were extracted and risk of bias(ROB) was assessed with the Cochrane Collaboration ROB tool. Meta-analyses were conducted using random effect models using the Review Manager(RevMan) computer software.

Results: Nineteen studies met inclusion criteria( $n=491$ participants at study completion) comprising male and female with age range 22-66 years. Two meta-analyses across 13 sub-group comparisons were performed. However, there were no RCTs on the impact of physical exercises on BMD in PLWHA. The result showed no significant change in $C D^{4+}$ count unlike a significant effect of 5.04 point $(95 \% \mathrm{Cl}:-8.49,-3.74, p=0.00001)$ for role activity limitation due to physical health(QoL sub-domain). Overall, the GRADE evidence for this review was of moderate quality.

Conclusions: There was evidence that engaging in moderate intensity aerobic exercises (55-85\% Maximum heart rate-MHR), for 30-60 min, two to five times/week for 6-24 weeks significantly improves role activity limitation due to physical health problems, otherwise physical(aerobic or/and resistance) exercises have no significant effects on CD4 ${ }^{+}$ count and other domains of QoL. Also, there is lack of evidence on the impact of exercises on BMD in PLWHA due to the paucity of RCTs. The moderate grade evidence for this review suggests that further research may likely have an important impact on our confidence in the estimate of effects and may change the estimate.
\end{abstract}

Keywords: HIV, Aerobic exercise, Resistance exercise, $\mathrm{CD}^{4+}$ cell count, QoL, Systematic review

\footnotetext{
* Correspondence: sam.ibeneme@unn.edu.ng

${ }^{1}$ Department of Medical Rehabilitation, Faculty of Health Sciences, University

of Nigeria, Enugu Campus, Enugu, Nigeria

${ }^{4}$ Clinical Trial Consortium University of Nigeria, Nsukka, Nigeria

Full list of author information is available at the end of the article
}

(c) The Author(s). 2019 Open Access This article is distributed under the terms of the Creative Commons Attribution 4.0 International License (http://creativecommons.org/licenses/by/4.0/), which permits unrestricted use, distribution, and reproduction in any medium, provided you give appropriate credit to the original author(s) and the source, provide a link to the Creative Commons license, and indicate if changes were made. The Creative Commons Public Domain Dedication waiver (http://creativecommons.org/publicdomain/zero/1.0/) applies to the data made available in this article, unless otherwise stated. 


\section{Background}

Human immunodeficiency virus (HIV) infection persists as a global public health issue [1] and is presently regarded as a chronic condition [2] since the advent of Highly Active Antiretroviral therapy (HAART). This is a sequel to the significantly improved life expectancy in people living with HIV (PLWHA) who are HAART-experienced [3]. This view is given further credence by the decreasing number of HIV-related deaths post-HAART era, down from the extreme point of 2.3 million in 2005 to an estimated 1.0 million in 2016 [4]. However, high incidence of comorbidities has been recorded in PLWHA, and might be due to the high rate of metabolic abnormalities resulting from toxic side effects of antiretroviral therapy(ART) [5]. These include low bone mineral density (BMD), and consequent high risk of fracture [6], cardiovascular diseases [7]' and instability of fat metabolism [8], which may be amenable to physical exercises.

Several research studies have supported the role of physical exercise as a complementary alternative therapy in the management of chronic illnesses, and apparently both aerobic and resistance exercises are beneficial to PLWHA [9].

For instance, contemporary literature supports the conclusion that exercise has been the key strategy to improve lean body mass, cardiovascular fitness [10], improve strength [11], change mood state [5], increase $\mathrm{BMD}$, reduce risk of fracture and invariably enhance quality of life (QoL) in PLWHA [12]. These developments may be attributed to the regulatory effects of structured exercise on immune function and probably as a result of expressive traction of muscles to the bones during training protocols.

Structured physical exercise at different intensities and duration has been shown to improve mental health, QoL, immune and physical function in PLWHA compared to an inactive lifestyle [3]. Aerobic exercise, when carried out for 16 weeks ( $30 \mathrm{~min}, 3$ times/wk) at a moderate intensity, resulted in either an increased or a stable $\mathrm{CD}^{4+}$ cell count which improves resistance to infection [5]. In fact, Maduagwu et al. [13], reported a significant improvement in the $\mathrm{CD}^{4+}$ cell in a pre-test and post-test 12 week (40 min, 3 times/wk) experimental study. Similar findings were reported by Ezema et al. [14], who observed a significant increase in $\mathrm{CD}^{4+}$ cell count and $\mathrm{VO}_{2}$ max with exercise compared to the control in an 8-week (45-60 min) training program. However, Tiozzo et al. [15], reported a stable $\mathrm{CD}^{4+}$ cell count with exercise during a 12-week intervention (45-60 min, 3 times/week) study, unlike the control who recorded a significant decrease. Similarly, structured resistance exercise also triggers a specific immune response in PLWHA as reported by Zanetti et al. [16] who demonstrated that resistance exercise for 12 weeks (3 times/week) is effective in boosting the $\mathrm{CD}^{4+}$ and $\mathrm{CD}^{8+}$ cell counts with consequent improvement in the integrity of the immune system. Furthermore, Anandh [17] also reported an increase in the $\mathrm{CD}^{4+}$ cell count, marked improvement in functional capacity and positive changes in QoL in PLWHA after a 12-week progressive resistance exercise (60 min, 3times per week) intervention. Meanwhile, a significant increase in the BMD and maximum muscle strength was observed after strength training, 3 times per week, for 12 weeks [12]. However, it is by investigating the unique impact of physical exercises through relevant studies in PLWHA that its physiological and therapeutic effects on the immune system, BMD, and Qol, in this population may be determined.

Overall, there are mixed reports on whether there are therapeutic benefits associated with physical exercises on the immune system, BMD, and QoL in PLWHA. Therefore, a systematic review of the literature should be conducted to provide a synthetic knowledge that is required to guide practice. To the best of our knowledge, this has not been done and was the focus of this review. Thus, the aim of this systematic review was to determine the impact of physical exercises on immune function, BMD, and QOL in patients with HIV.

\section{Methods}

This systematic review was certified according to the International Prospective Register of Systematic Reviews (PROSPERO) on 27 June 2017 (registration number PROSPERO 2017: CRD42017069068).

\section{Eligibility criteria}

Eligibility criteria considered for selecting studies in the review include:

Inclusion criteria:

1. Type of studies Original research manuscripts in peer-review journals and conferences proceeding were included if published in the English Language. This design only included RCTs in the review when the following objective was evaluated: the effects of physical exercises on immune function, BMD and QoL in PLWHA.

2. Type of participants

The review included studies involving adult human participants aged $\geq 18$ years. Only studies that investigated PLWHA were included, however, no specific limitation was considered with respect to the setting of the studies. The included studies were mainly carried out in clinics, health centers, hospitals or community care settings.

3. Type of intervention

RCTs of physical exercise (either/both aerobic and resistance exercise) intervention for PLWHA were included in the review, which was not 
restricted to specified dosage, form, intensity, frequency and duration of intervention or follow-up period after aerobic intervention or limited to weight training, isometric and isotonic strengthening for resistance exercise in PLWHA.

4. Timing

There was no specified length of the interventions or the follow-up of outcomes.

5. Types of outcome measures

Studies that reported changes in outcome measures of immune function (e.g. $\mathrm{CD}^{4+}$ count or viral load), BMD (e.g. osteoporosis or osteopenia) and QOL (e.g. physical function, the performance of social roles, emotional status, and cognitive function) in PLWHA were included in the review. Studies were included regardless of whether an outcome of interest was accounted for as a primary or secondary outcome in the first article, so far as a clear analysis was carried out for each outcome. All outcome variables were collated as they were accounted for in individual studies, and the original description in those individual studies was not modified. Clinical results, detailed by individual studies were analyzed and graded.

Exclusion criteria:

1. Studies without an exercise or physical activity component.

2. Narrative review syntheses, systematic reviews, opinion papers, letters and any publication without primary data and/or explicit description of the methods.

3. For duplicate publications from the same study, the most recent or most comprehensive publication was used.

\section{Information sources and search strategy}

A search strategy was formulated and piloted as shown in Additional files 1,2 and 3. This was based on the guidelines of the Cochrane Handbook for Systematic Reviews [18] and advice for Health Care Review by the Centre for Reviews and Dissemination [19]. This formulated strategy was further adapted for use in other databases. Eight databases (CINAHL, the Cochrane Library, ProQuest, AMED, MEDLINE, PubMed and Web of Science Core Collection) and trial registers and directory of open-access repository websites were searched by the reviewers - FOR and EFE - using controlled vocabularies and keywords: HIV/AIDS, Seropositive, aerobic exercises, resistance exercises, strengthen exercises, physical exercises, exercise program, exercise intervention, $\mathrm{CD} 4^{+}$, immune function, bone mineral density, bone turnover, and QoL. Additionally, searches were performed from the reference lists of identified studies.
Study record, selection process, and data management Literature search results were exported into RefWorks to check for duplication of studies. Bibliographic records were exported from RefWorks into Microsoft Excel (Microsoft. Microsoft Excel. Redmond, Washington: Microsoft, 2010. Computer Software) [20] to facilitate the management and selection of articles for inclusion. Eligibility questions and forms for the screening of the studies included in the review were then developed, piloted and subsequently refined. The title, abstract and full texts of selected studies were independently screened for eligibility by F.I.O and E.F.E based on the review eligibility criteria. Differences of opinions occurring at any stage regarding inclusion or exclusion were resolved by discussion and reflection, in consultation with S.C.I.

\section{Quality appraisal and risk of bias}

Adopting the Cochrane Collaboration Tool for Risk of Bias Assessment (Table 8.5a of the Cochrane Handbook for Systematic Reviews of Interventions) [21], risk of bias for each of the included studies were evaluated by two authors in six key domains: (i) selection bias (random sequence generation, allocation concealment); (ii) performance bias (blinding of personnel and participants); (iii) detection bias (blinding of outcome assessments); (iv) bias due to attrition (incomplete outcome data, including dropouts and withdrawals); (v) reporting bias (selective reporting) and (vi) other bias (other sources of bias not elsewhere addressed) (Additional file 4) [18].

The procedures undertaken to assess each domain for each study was explicitly described and rated as 'high risk' or 'low risk'. The risk of bias in a study was reported as unclear if there were insufficient details in the original study. In such instances, the study investigators were contacted to provide the required details. The judgments for the risk of bias was made independently by the first reviewer and the same with the second reviewer, based on the criteria for judging the risk of bias (Additional file 4) [18]. Both reviewers made judgments regarding the risk of bias independent of each other. Areas of differences were resolved by discussion and reflection, or in consultation with S. C. I.

\section{Data item}

Data were collected from variables including authors' references, participants' characteristics, inclusion and exclusion criteria, study sample size, components of the intervention, the intervention setting, who delivered the intervention, the duration of the intervention and follow-up (where available), attrition rate, aspects of outcome assessed, the outcome measurement, methods/ techniques, results, conclusions and funding sources. 


\section{Data synthesis and assessment of heterogeneity}

The review question of the impact of physical exercises on immune function, BMD, and QOL, in patients with HIV/ AIDS, was answered. In doing this, all quantitative study outcomes which analyzed the effectiveness of these interventions were presented, considered and combined in a proof table. The Proper statistical method was used for different variables: for a continuous variable, weighted mean differences were applied when outcomes are uniform or standard mean difference when different outcomes are used with 95\%: CI while for a dichotomous variable, the Risk ratio was applied with 95\%: CI. This review also includes a meta-analysis to find pooled effect sizes across studies, using a random-effects model relying on the level of heterogeneity of intervention effects. Heterogeneity was assessed using the Cochrane's $\chi^{2}$ test $(10 \%$ significance level) and Higgins $\mathrm{I}^{2}$ for which values of 25 , 50 , and $75 \%$ shows low, medium and high heterogeneity respectively as stipulated by the guidance in the Cochrane Handbook for Systemic Reviews of Interventions [19].

\section{Data and sensitivity analysis}

Investigation and presentation of outcomes were made using the primary outcome. Studies with homogenous characteristics in terms of design, intervention, and comparator(s) were pooled together for meta-analysis using a random-effects model [18]. Heterogeneous studies were interpreted by narrative synthesis following the guidelines of the Centre for Reviews and Dissemination to explore the relationship and findings between the included studies [19]. Sensitivity analysis was done to decide the impacts of studies with a high risk of bias on the general outcomes with and without these studies.

\section{Rating quality of evidence and strength of recommendation}

The quality of evidence of the studies was evaluated to determine the strength of recommendation in the systematic review. This was judged utilizing the Grading of Recommendations Assessment Development and Evaluation (GRADE) approach [22] which comprise consistency; design; directness; precision; publication bias and study limitations. The individual study was graded as high risk of bias or low risk of bias, and then again individual evidence statement for this review was graded from 'High Quality' to 'Very Low Quality' according to the criteria (Additional file 5).

\section{Results}

\section{Search result}

Three different searches were carried out sequentially during the course of this study using the three-primary outcomes separately in the search strategy.

1. Immune function
Searches of all sources found 127 citations, and after duplicate removal, 79 were potential for evaluation of which 16 publications were considered after topic and abstract screening for inclusion. When full-text screening was concluded, 13 articles met the inclusion criteria $[13,14,16,17$, 23-31, 36] (Additional file 6. PRISMA flow Diagram).

2. Bone mineral density

The result from all sources gave 18 citations, 6 duplicates were removed and after a full-text screening of 12 articles, none met the study inclusion criteria. (Additional file 7. PRISMA flow Diagram).

3. Quality of life

The search strategy resulted in 251 citations, after deduplication and abstract review, 12 full citations were reviewed to determine whether they met inclusion criteria which after review, 10 studies met the inclusion criteria [17, 23, 24, 27, 32-37]. (Additional file 8. PRISMA flow Diagram).

\section{Reasons for exclusion}

Three full-text articles retrieved (for immune function) were excluded because studies [38-40] did not assess immune function as an outcome. For the QoL, the 2 studies [41, 42] excluded were non-randomized clinical trials. For bone mineral density, none of the studies were RCT and therefore were all excluded.

\section{Included studies}

\section{Immune function}

All the study that reported immune function as an outcome were all RCTs. 10 studies used aerobic exercise [13, 14, 23-30], 2 studies utilized resistance exercise [16, 17] while 1 study [31] combined both exercises as an intervention. Studies of aerobic exercise intervention included 7 studies with no exercise group [23, 25, 26], maintain normal daily activity group [13, 27, 30], and high-intensity aerobic exercise group [27, 29], while Ezema [14], Ogalha [24]' and Terry [28] utilized conventional therapy, counselling, and soft stretching plus relaxation as control, respectively. Resistance exercise studies on the other arm also had no exercise group [17] and maintain normal activity group [16] while the combined study [31] had no exercise group as control (Table 1).

\section{Quality of life}

Studies that assessed QoL as an outcome were all RCTs. Five studies had aerobic exercise as intervention [23, 24, $27,32,33,34]$, three studies had resistance exercise as an intervention $[17,32,35]$ and two studies combined both interventions [36, 37]. Aerobic exercise and combined studies had no exercise [23, 33, 37], maintain daily 


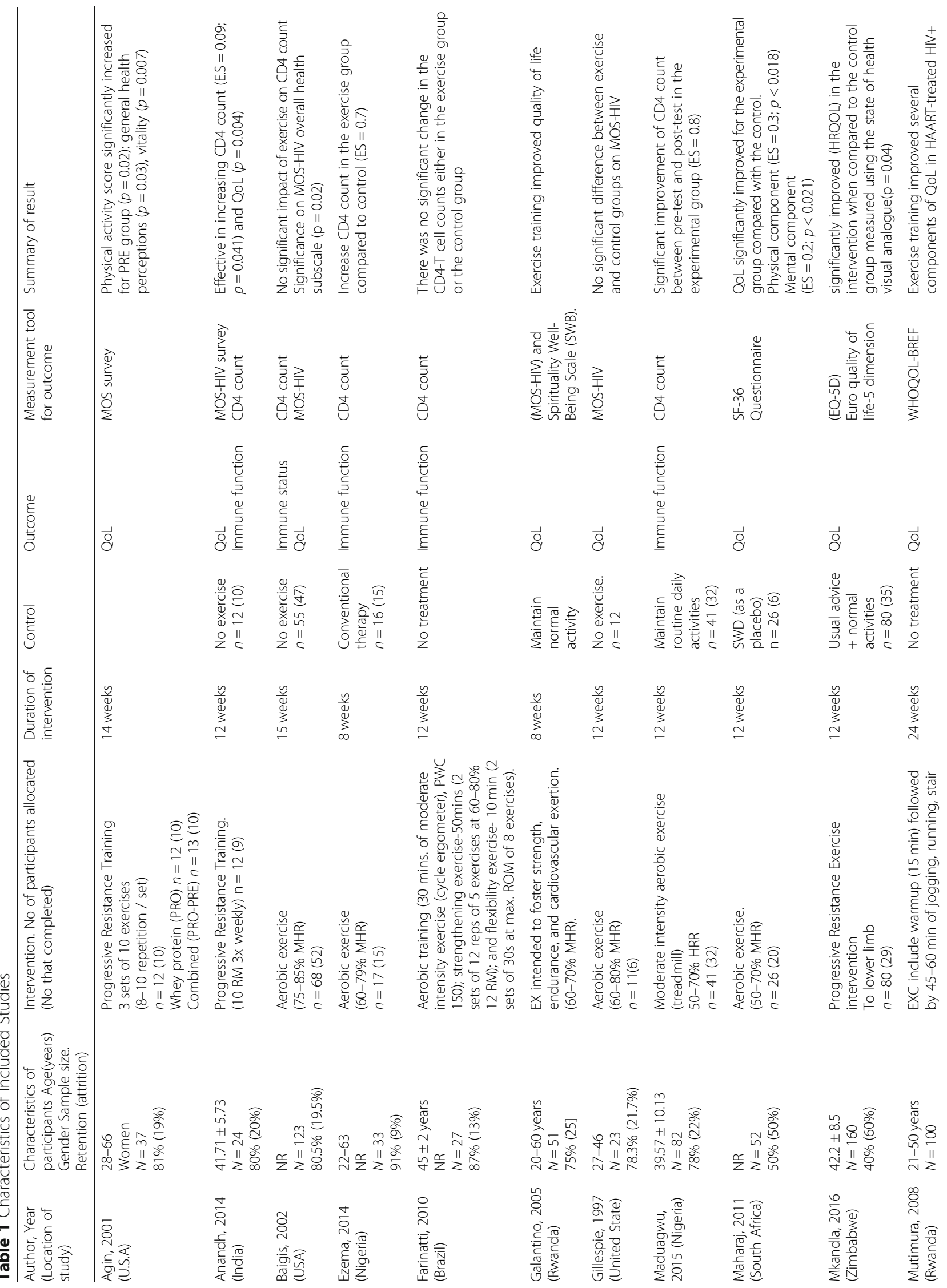




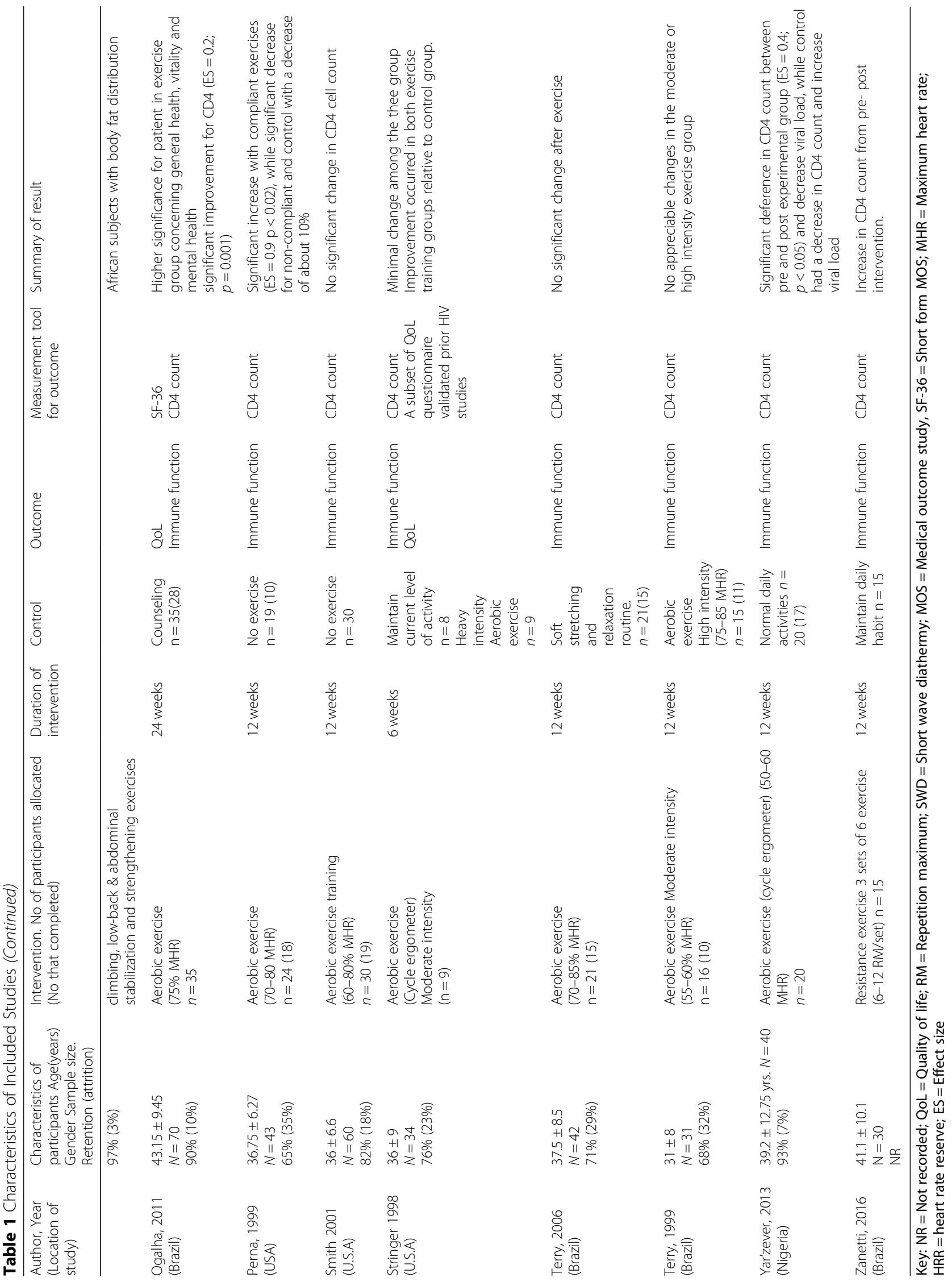


activity $[27,36]$, and Short-wave diathermy as a placebo [34], with counselling [24] groups as control while resistance exercise studies had no exercise [17], usual advice plus normal activities [35] as control groups. One of the three studies for resistance exercise assessed the effects of co-intervention of progressive resistance exercises (PRE)-and Whey protein [32]. This study also included a comparison group of whey protein only (Table 1 ).

\section{Participants of included studies Immune function}

A total of 639 participants were included in this arm of the review (i.e. participant recorded at baseline). Participant were all HIV male and female adults with $\mathrm{CD}^{4+}$ cell count ranging from $<150$ cells $/ \mathrm{mm}^{3}$ to $>850$ cells $/ \mathrm{mm}^{3}$ with age range $22-63$ years and were on a HAART regimen. Five studies had participant located in Brazil [16, $24,28,29,31]$, one in India [17], three in Nigeria [13, 14, 30], and four in U.S. A [23, 25-27] (Table 1).

\section{Quality of life}

Participants (661) included in this arm of the review were both male and female PLWHA at various stages of the disease, with $\mathrm{CD}^{4+}$ cell count $<100$ cells $/ \mathrm{mm}$ [3] to $>1000$ cells $/ \mathrm{mm}$ [3]. The age ranged from 28 to 66 years and their location were Brazil [24], India [17], South Africa [34], U.S.A [23, 27, 32, 33,], Rwanda [36, 37] and Zimbabwe [35] (Table 1).

\section{Outcome of intervention}

All but four of the included studies assessed for immunological function using $\mathrm{CD}^{4+}$ cell count or viral load [32-34]. Ten studies assessed QoL outcome using Medical Outcomes Study (MOS) Health Survey [17, 23, 32, 33], 36-Item short-form Health survey MOS [24, 27, 34, 36], Euro quality of life-5 dimensions (EQ-5D) [35] and World Health Organization Quality of Life (WHOQOL)-BREF questionnaire [37]. Three studies assessed physical endurance [23, 26-28], but Ezema [14] and Perna [25] accessed cardiopulmonary function while Agin [32], Mkandla [35], and Zanetti [16] assessed muscle strength. Also, four studies assessed lipid profile [24, 27-29] while Zanetti [16] assessed inflammatory markers.

\section{Risk of Bias in included studies}

Tables 2 and 3 provides information on quality appraisal and risk of bias in the included studies. All the included studies carried out random sequence generation and were free of selective reporting bias. Four studies [13, $17,23,32]$ described the sequence for allocating participants into study groups. Four studies $[17,26,34,35]$ further reported assessor and personnel blinding and were thus judged low risk in this regard.
Overall, 571 participants withdrew from the included studies accounting for $\sim 54 \%$ withdrawal rate $(571 / 1062$ participants at baseline). Withdrawal rates within individual studies ranged from 3\% [37] to 60\% [35] (Table 1). However, a high risk of bias due to attrition exists as 15 of the 19 included studies (78.9\%) reported withdrawal rates of $>15 \%$ while 1 study [16] did not provide information on incomplete outcome reporting. The remaining 3 studies were judged the low risk of bias due to attrition (25\%) with withdrawal rates of $<15 \%[14,24$, 30]. The withdrawal rate between comparison groups was similar in most groups. Almost all the included studies mentioned participant who was not complying with their exercise intervention or withdrew from the study. (Table 1 shows the proportion of participants who dropped from individual studies). All Authors but one [16] reported information on adherence to the exercise intervention. Adherence rate ranged from 40 to $93 \%$ [30, 35].

\section{Narrative synthesis}

Immune function One study [31] which assessed immune function, and which was not included for meta-analysis combined aerobic and resistance exercise among 27 HAART treated HIV-infected patients (age $45 \pm 2$ years). This intervention was carried out in Brazil for 12 weeks whereby the exercise group $(n=19)$ were involved in aerobic training (cycle ergometer) for $30 \mathrm{~min}$ of moderate intensity, strengthening exercise $(2$ sets of 12 repetitions of 5 exercises at $60-80 \% 12$ Repetition Maximum) for $50 \mathrm{~min}$ and flexibility exercise (2 sets of $30 \mathrm{~s}$ at maximum range of motion of 8 exercises) while the control group $(n=8)$ received no treatment. Immune function $\left(\mathrm{CD}^{4}\right.$ and $\left.\mathrm{CD}^{4} \%\right)$ were determined by specific monoclonal antibodies using fluorescein isothiocyanate and phycoerythrin monoclonal antibodies using a whole blood staining method. The study reported no significant change in the $\mathrm{CD}^{4} \mathrm{~T}$-cell count in either the exercise group or the control group $\left(p=0.19\right.$ for $\mathrm{CD}^{4}$ T-cells and $p=0.22$ for $\mathrm{CD}^{4} \%$ ) [31].

Quality of life Similarly, two studies [36, 37] which investigated QoL also employed a combined exercise approach in PLWHA. In Rwanda, Mutimura [37] recruited 100 HIV individuals (21-50 years) with body fat redistribution (BFR) that were on HAART for greater than 6 months to find out the effect of exercise training on QoL. The participants (exercise group) were involved in a 6-month supervised exercise (EXS) programme which consists of warm-up exercise followed by 45-60 min of jogging, running, stair climbing, low-back \& abdominal stabilization and strengthening exercises while the control group did not undergo any treatment. The outcome of interest (i.e. QoL) was measured at baseline and after 


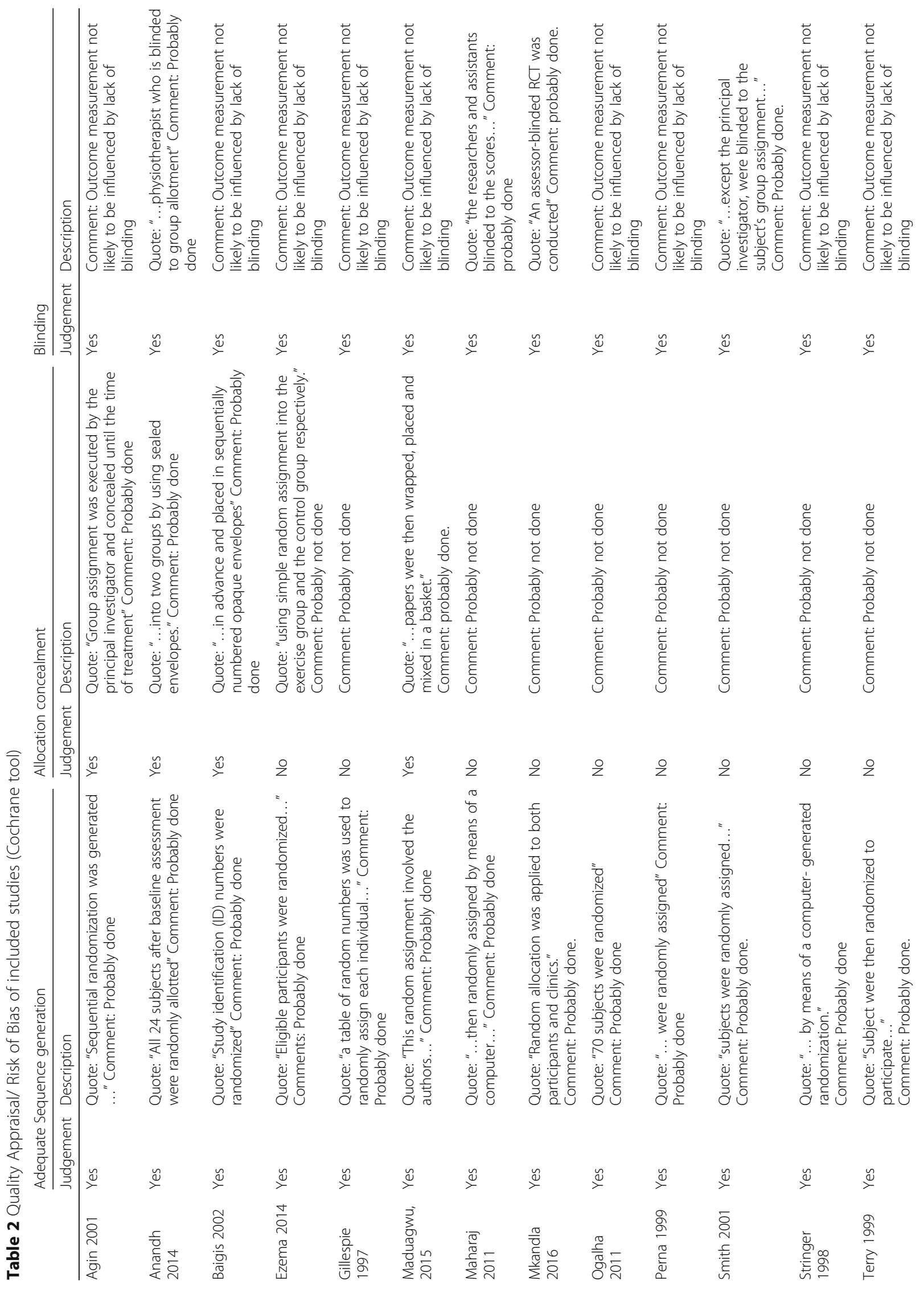




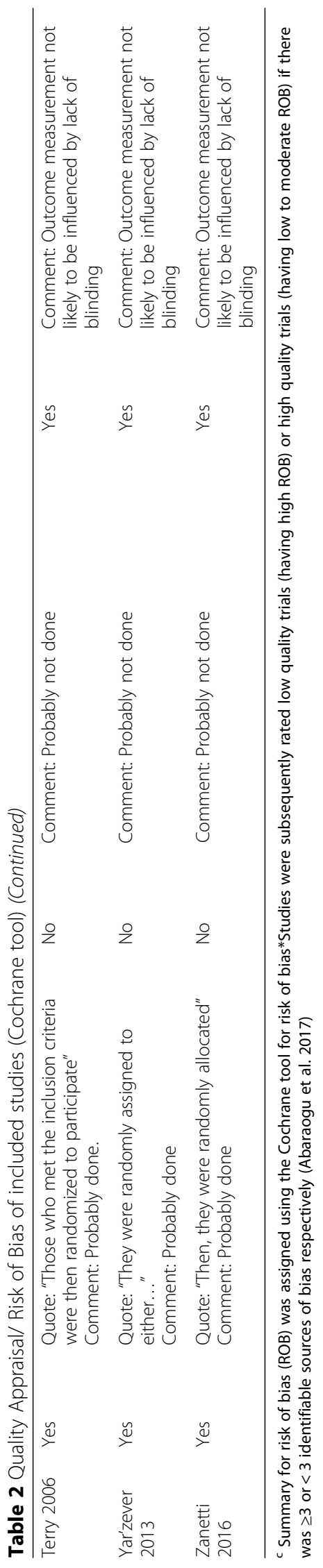




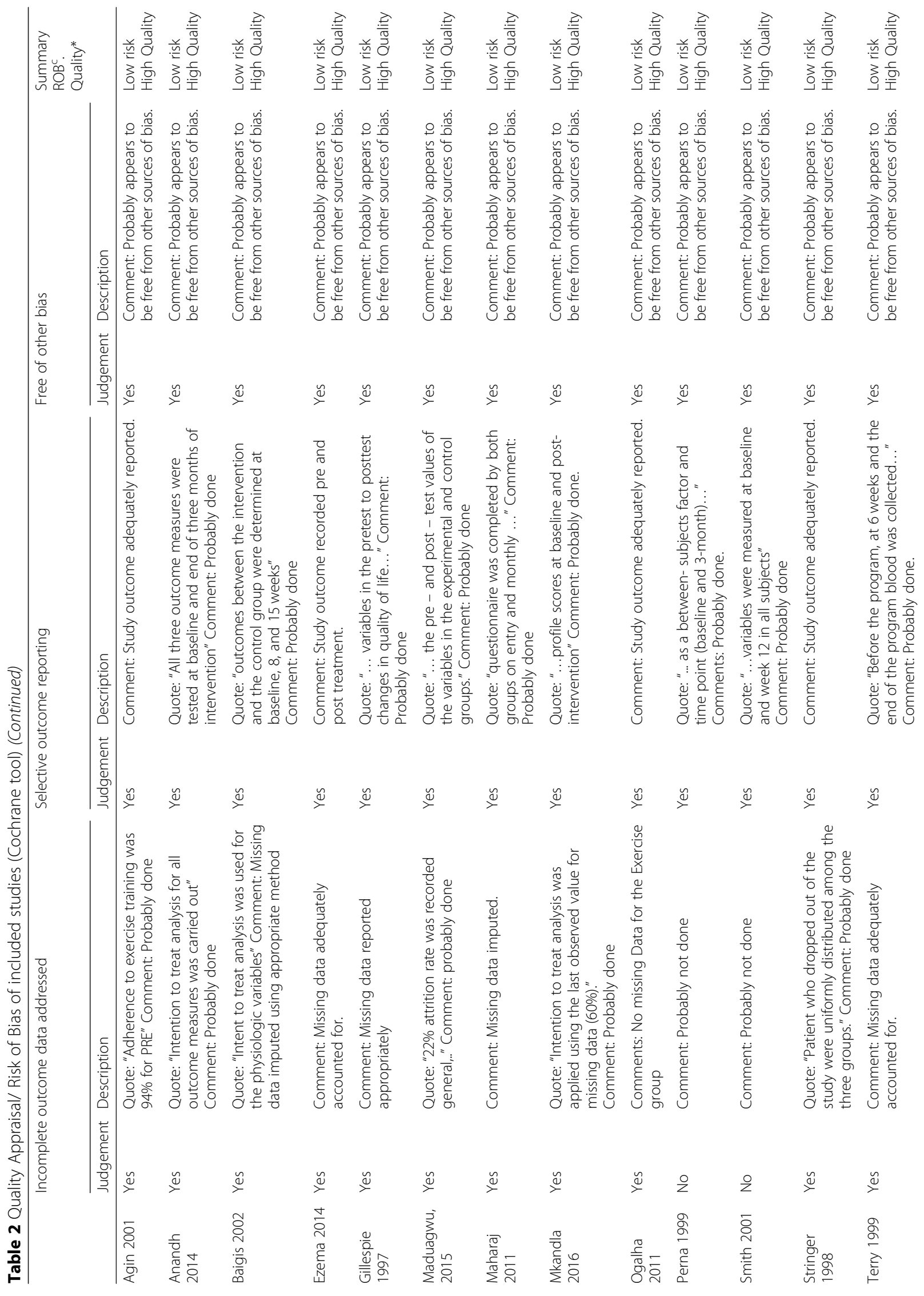




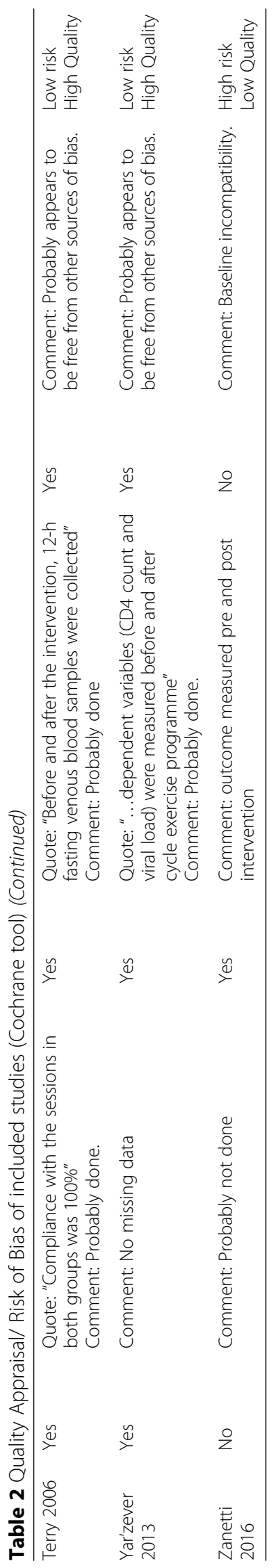


Table 3 Risk of bias in individual studies for combined Studies

\begin{tabular}{|c|c|c|c|c|c|c|c|c|c|}
\hline \multirow[t]{3}{*}{ Study } & \multicolumn{9}{|c|}{ Sources/Potential sources of bias ${ }^{a}$} \\
\hline & \multicolumn{2}{|l|}{ Selection bias } & \multirow{2}{*}{$\begin{array}{l}\text { Performance bias } \\
\text { Participants and } \\
\text { personnel blinding }\end{array}$} & \multirow{2}{*}{$\begin{array}{l}\text { Detection bias } \\
\text { Blinding of outcome } \\
\text { assessment }\end{array}$} & \multirow{2}{*}{$\begin{array}{l}\text { Bias due } \\
\text { to attrition } \\
\text { Incomplete } \\
\text { data }\end{array}$} & \multirow{2}{*}{$\begin{array}{l}\text { Reporting } \\
\text { bias } \\
\text { Selective } \\
\text { reporting }\end{array}$} & \multirow{2}{*}{$\begin{array}{l}\text { Other } \\
\text { bias }\end{array}$} & \multirow{2}{*}{$\begin{array}{l}\text { Summary } \\
\text { of bias }\end{array}$} & \multirow{2}{*}{$\begin{array}{l}\text { Quality } \\
\text { index }\end{array}$} \\
\hline & $\begin{array}{l}\text { Random sequence } \\
\text { generation }\end{array}$ & $\begin{array}{l}\text { Allocation } \\
\text { conceal-ment }\end{array}$ & & & & & & & \\
\hline $\begin{array}{l}\text { Mutimura } \\
\text { et al. } 2008\end{array}$ & No & Yes & Yes & Yes & No & No & - & High & Low \\
\hline $\begin{array}{l}\text { Farinatti } \\
\text { et al. } 2010\end{array}$ & No & Yes & No & Yes & No & No & $\begin{array}{l}\text { Small } \\
\text { sample }\end{array}$ & Low & High \\
\hline $\begin{array}{l}\text { Galantino } \\
\text { et al. } 2005\end{array}$ & No & Yes & Yes & Yes & No & No & - & High & Low \\
\hline
\end{tabular}

The Cochrane's tool was used to determine and summarize possible sources of risk of bias in the included studies (Cochrane 201) (Yes indicates the presence of or potential presence of a source of bias)

a summary risk of bias in included studies was presented

${ }^{b}$ studies were subsequently rated as low quality trials (i.e. having high risk of bias) or high quality trials (i.e. having low to moderate risk of bias if there was $\geq 3$ or $<3$ identifiable sources of bias respectively (Abaraogu et al. 2017)

6 months using WHOQOL-BREF (short-form instrument) evaluating physical, psychological, independence and social relationship domains. Findings from this study state that over the 6-month training period, significant improvements were observed in BFR + EXS group for the psychological, independence, social relationships $(p<0.001)$ domains of QoL compared to BFR + noEXS group [37]. The other study also with a combined intervention on functional outcomes and QoL [36] was also carried out in Rwanda with 38 PLWHA (20-60 years) on HAART greater than/ 3 months. The EXS group received 8 weeks of exercises with the goal to foster strength, endurance, and cardiovascular exertion while the control group maintained normal daily activities. QoL outcome was assessed using the Medical Outcome Short Form (MOS-HIV) and report states that there is an improvement in QoL from participants in EXS group when compared to control group in overall health perception subscale $(p=0.04)$ [36].

The above studies $[36,37]$ from inference have a common relationship in setting, type of intervention, study design and outcome of interest. Results from both studies are also similar suggesting a positive effect of combined aerobic and resistance exercise on PLWHA on HAART (> 3 months). The robustness of this synthesis is low and should be interpreted with caution because of the quality attributed to the studies (having a high risk of bias) judging by Cochrane risk of bias assessment tool [18].

\section{Meta-analyses - effects of interventions}

This review conducted two meta-analyses across thirteen sub-group comparisons which included meta-analyses for immune function $\left(\mathrm{CD}^{4+}\right.$ cell count) and QoL. The sub-group comparisons of the meta-analyses were:

1) Aerobic exercise compared to no exercise as a control

2) Aerobic exercise compared to normal routine activity as control
3) Moderate intensity aerobic exercise compared to high-intensity aerobic exercise

4) Aerobic exercise compared to other controls (conventional, counseling and soft stretching plus relaxation)

5) Resistance exercise compared to control (no exercise and maintain normal routine activities).

6) Physical activity limitation due to health

7) Role activity limitation due to physical health

8) Bodily pain

9) General health perception/overall

10) Vitality/Energy

11) Social limitation due to physical/emotional problems

12) Role activity limitation due to emotional problems

13) Mental health.

Three of the included studies compared aerobic exercise with no exercise control group [23, 25, 26]. Three studies compared aerobic exercise with normal routine activity [13, 27, 30]. Two studies compared moderate-intensity aerobic exercise to high-intensity exercise [27, 29]. Ezema [14], Ogalha [24] and Terry [28], compared aerobic exercise with conventional therapy, Counselling, and soft stretching plus relaxation as control respectively (Table 1). Two studies compared resistance exercise to either no exercise or maintain normal activities [16, 17]. For the QoL outcome, three studies included in the review [24,33,34] compared aerobic exercise with control. In all domains of QoL, only role activity limitation due to physical health showed a significant difference. Meta-analyses were limited for the QoL due to the outcome reported and outcome tool for the remaining studies.

\section{Heterogeneity}

Heterogeneity $(p<0.1)$ was evident in the 2 meta-analyses which could be as a result of the differences in gender, location, and type of intervention. Sensitivity analysis was carried out with those greater than two studies since 
heterogeneity exists in the meta-analysis, thus the results and reasons include:

\section{Immune function $\left(\mathrm{CD}^{4+}\right.$ count cell)}

Most of the nineteen included studies assessed $\mathrm{CD}^{4}$ ${ }^{+}$cell count as an immunological outcome. Five sub-group meta-analyses were performed for $\mathrm{CD}^{4+}$ cell count. All the analyses demonstrated no statistically significant change in the $\mathrm{CD}^{4+}$ cell count between comparison groups Weighted Mean Difference: -28.02 cells $/ \mathrm{mm}^{3}$, 95\% CI: -61.09, 5.04, $p=0.10$ ) (forest plot- Fig. 1). Results demonstrated a non-significant trend towards an increase in $\mathrm{CD}^{4+}$ cell for participants in the aerobic exercise compared to no exercise; aerobic exercise compared to normal routine activity; moderate intensity aerobic compared to high-intensity aerobic exercise; aerobic exercise compared to other controls and resistance exercise compared to control. The results of the metaanalyses indicated no difference in the $\mathrm{CD}^{4+}$ cell count for aerobic exercise compared to no exercise; aerobic exercise compared to normal routine activity; moderate intensity aerobic compared to high intensity aerobic; aerobic exercise compared to other controls. Likewise, no difference in $\mathrm{CD}^{4+}$ cell count was found for resistance exercise compared to control.

II. Heterogeneity $-\mathrm{CD}^{4+}$ count All the sub-group meta-analyses were statistically significant for heterogeneity $(p<0.1)$. Sensitivity analyses did not indicate a change in the overall effects of exercise on $\mathrm{CD}^{4+}$ cell count.

III. Quality of life

Ten of the nineteen included studies assessed QoL. Meta-analyses were performed for three studies

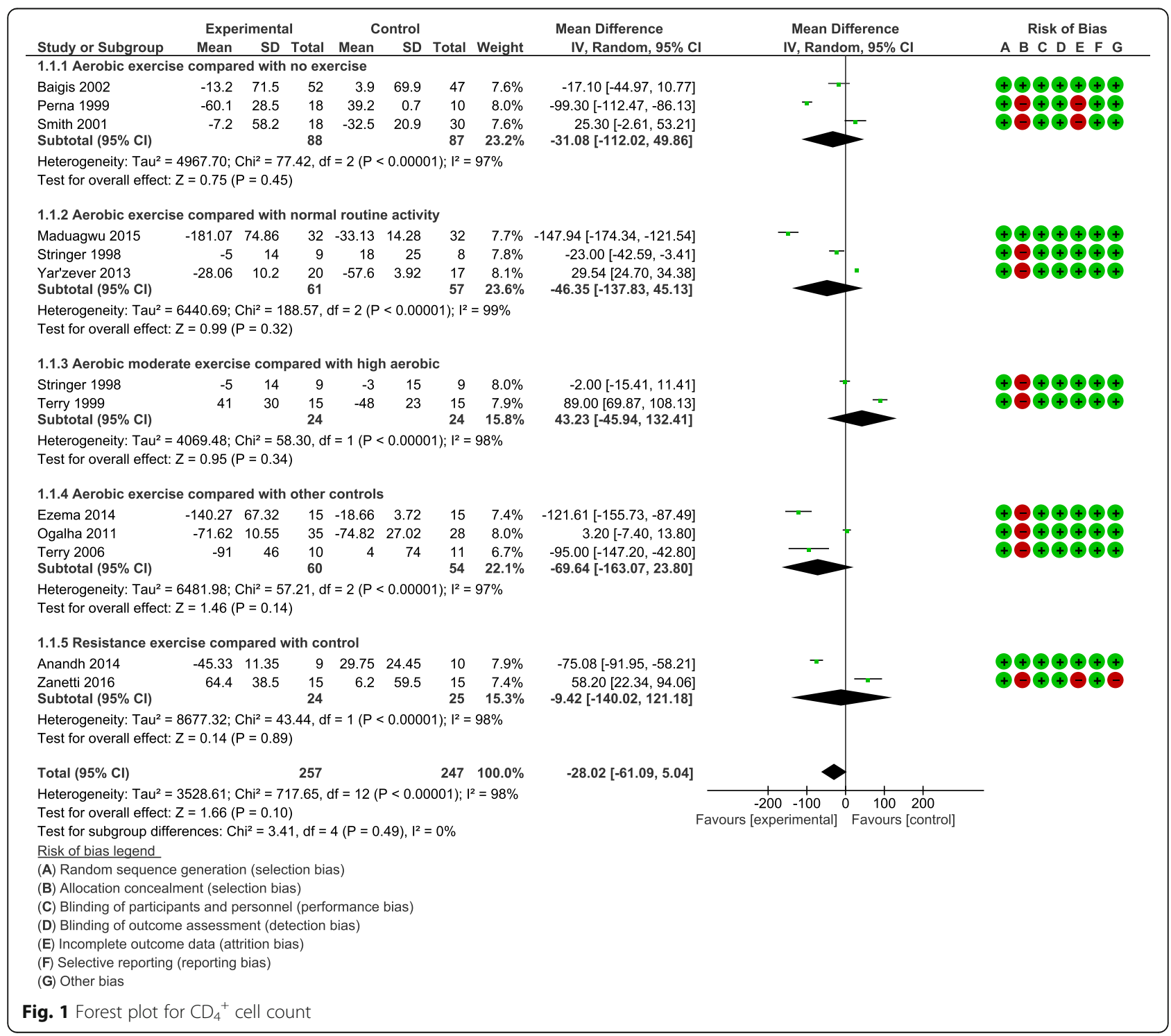


$[24,33,34]$ on 8 sub-domains for QoL. The result of meta-analyses showed no statistically significant difference in all but one sub-domain (role activity limitation due to physical health) (forest plotFig. 2). This represents a clinically important improvement in role activity limitation due to physical health compared to control (no exercise, placebo, and counseling).

IV. Heterogeneity - QoL

All but one sub-group meta-analyses were statistically significant for heterogeneity $(\mathrm{p}<0.1)$. Sensitivity analyses indicated the same overall effect of exercise on QoL.

V. Grade rating

The effect estimate demonstrated the overall significant effect of 5.04 points (95\% CI: $-8.49,-3.74$, $p<0.00001)$ for role activity limitation due to physical health (Qol sub-domain) when comparing aerobic exercise group to controls, which can be accepted as moderate evidence. The true effect is likely to be close to the estimate of the effect, but there is a possibility that it may be substantially different. This outcome was downgraded from high to moderate GRADE quality of evidence, because of the inability of authors to conceal allocation in the assignment of participants to experimental and control groups.

\section{Discussion}

Meta-analyses for immune function $\left(\mathrm{CD}^{4+}\right.$ cell count) showed that neither aerobic exercise nor resistance exercise intervention carried out for a period of 8-24 weeks had an impact on $\mathrm{CD}^{4+}$ cell count of PLWHA. The results also showed that neither aerobic exercise nor resistance exercise is safe for medically stable adults living with HIV/ AIDS. This finding is based on few available reports/literature on the impact of either aerobic or resistance exercise on $\mathrm{CD}^{4+}$ cell count in HIV patients and also on participants that finished their exercise protocol prescription and for whom adequate follow-up data were provided.

Most of the studies that assessed $\mathrm{CD}^{4+}$ cell count were included in a meta-analysis [13, 14, 16, 17, 23-30, ]. Generally, evaluating either aerobic exercise or resistance exercise with controls among PLWHA suggests minute to no impact on $\mathrm{CD}^{4+}$ cell count. This agrees with the conclusion from previous reviews by Jaggers \& Hand [5]' Nixon [10], and O'Brien [43, 44]. Aside from these meta-analyses, individual studies that assessed $\mathrm{CD}^{4+}$ cell count reported increase in $\mathrm{CD}^{4+}$ cell count of effect size (Cohen's $d$ ) 0.9, 0.7, 0.8, 0.2, 0.9, 0.4, 1.2 [13, 14, 16, 17, 24, $25,30]$ respectively, suggesting a mean/pooled (0.73) large effect of both aerobic and resistance exercise on HIV patient while the remaining studies reported minimal or no change in $\mathrm{CD}^{4+}$ cell count $[23,26-29,31]$. Among the Ten studies that assessed the QoL as an outcome,
Meta-analyses conducted for three studies [24, 33, 34] suggest that aerobic exercise only demonstrated significant improvement in one sub-domain of QoL assessment (role activity limitation due to physical health). These findings give credence to an earlier review by O'Brien [44] that the QoL improved for physical function, role emotional, and mental health sub-domains among exercisers compared to non-exercisers.

Individual studies' results show that progressive resistance exercise group (PREG) tends to record improved physical activity score, general health perceptions, and vitality [32]. PREG group improved in QoL assessed by MOS scales $[17,23]$ and another using health visual ana$\log$ [35]. Aerobic exercise also significantly improved the QoL (physical and mental component; general health, vitality, and mental health) of the experimental group compared to the control $[24,34]$ respectively. Likewise, Stringer [27] reported an improvement for both moderate-intensity aerobic exercise and heavy intensity aerobic exercise when compared to the control group while combined intervention (aerobic and resistance) improved several components of QoL [36, 37]. In contrast, Gillespie et al. [33] reported no improvement between exercise and control group using MOS-HIV scale.

\section{Bone mineral density}

Evaluation of the impact of physical exercise on BMD was not included in this review due to the paucity of RCTs in PLWHA, assessing BMD as an outcome.

\section{Quality of evidence}

Since the interventions in this review were aerobic exercise and resistance exercise, the possibility of blinding participants and exercise supervisors, was not feasible. The exact impact of the absence of blinding on the extent and bearing of the treatment impact is unclear, and however, may constitute a high risk of performance bias [45-49]. On the other hand, some outcomes were self-reported, which also prompted a high innate risk of detection bias when blinding of members was unrealistic. The researchers chose not to downgrade studies for this 'risk of bias' item alone. However, reasons for allotting studies a high risk of bias were not due to lack of blinding. Furthermore, the GRADE evidence of this review was of moderate quality suggesting that further research may likely have an important impact on our confidence in the estimate of effect and may change the estimate.

\section{Conclusions}

\section{Implication for practice}

Engaging in moderate intensity aerobic exercises (55-85\% Maximum heart rate- MHR), for 30-60 min, two to five times per week for 6-24 weeks can lead to significant improvement in role activity limitation due to 


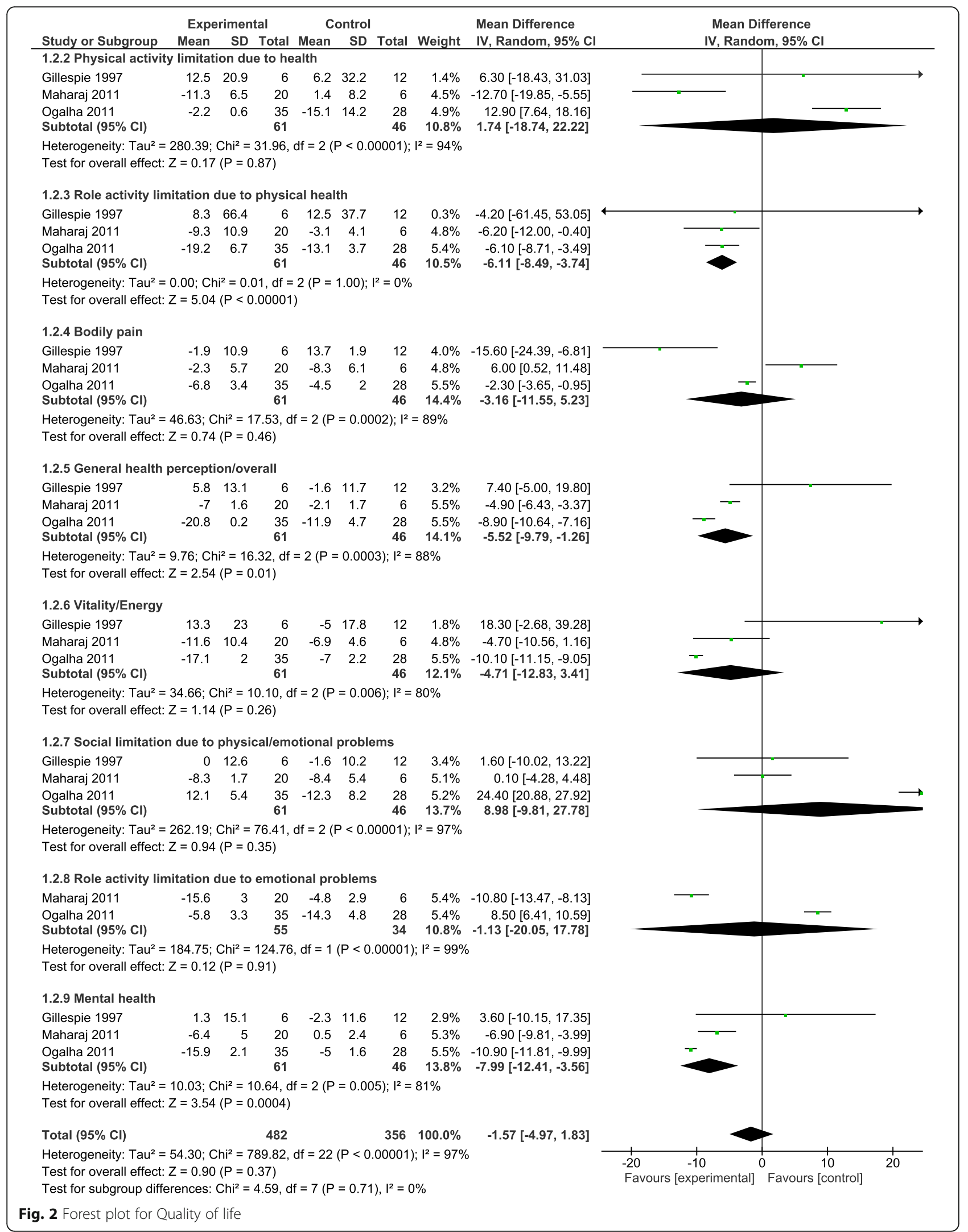


physical health problems (a sub-domain of QoL), otherwise physical (aerobic or/and resistance) exercises have no significant effects on immune function $\left(\mathrm{CD}^{4+}\right.$ cell count) and other domains of QoL. However, lack of RCTs on the effects of physical exercises on the BMD in PLWHA makes it difficult to reach a scientific conclusion that will guide practice. The findings from this study are very important because a previous study [50] has shown that functional limitations of PLWHA affect their care needs and ability to perform social roles such as employment. According to Crystal et al. [50], the limitation in complex roles among PLWHA - such as working at a job, working around the house, or going to school - was more prevalent than limitation in most specific physical tasks. Among physical tasks, limitation was more prevalent in energy-demanding activities including climbing stairs $(43 \%)$ or walking $>1$ block $(26 \%)$ than in self-care tasks such as bathing and dressing (14\%). Moreover, symptom intensity, pain, and fatigue were strongly associated with these limitations. Therefore, the evidence from this study recommends physical exercises (specifically moderate intensity aerobic exercises) as an effective clinical tool for addressing the wellbeing of PLWHA such that improved management of these disease symptoms using physical exercises might improve physical and social functioning at no extra financial cost, and with little or no side effects to the PLWHA.

\section{Implication for research}

The research found few studies on the impact of physical exercises (i.e. aerobic or resistance exercise or the combination of both exercise types) on immune function, and QoL for adults living with HIV, but none on the BMD. Moreover, the few studies identified are also of relatively low quality. All these reasons cumulate and emphasize the need for further research studies in this area. The lack of RCTs on the impact of physical exercises on BMD in PLWHA is an important gap that needs to be addressed in future studies. The increasing reports that bone demineralisation is amenable to physical exercises in non-HIV infected population [51] highlights the possibility of the translational relevance of such studies in HIV/HAART-experienced PLWHA considering the fact that HIV/HAART are associated with bone loss. The study population included both younger and older adults, as well as both male and female participants without considering the variation in the age of participants which could possibly influence the results. The small number of participants per study, that completed the exercise intervention $(n=6-52)$ suggest that the included studies may have lacked sufficient power to detect treatment effect or that the sample size is smaller than what would be required to detect a clinically important benefit. Therefore, further studies should address the limited number of RCTs and the weaknesses of the available studies as already mentioned above, otherwise it will be difficult to reach a scientific conclusion that will guide practice on the effects of exercises on such parameters as $\mathrm{CD} 4^{+}$cell count, BMD, and other domains of the QoL.

\section{Limitation of study}

The findings of this review might be limited for the following reasons: i) This review included a small number of studies that actually met the study criteria, Meta-analyses conducted involved a maximum of 3 studies and had a range of 24-88 participants in each sub-group. In addition, the generalizability of the results may be limited by the fact that the general findings among individuals who complied with the exercise prescriptions might not reflect the genuine experience of exercise among adults living with HIV/AIDS. However, since all the studies were RCTs, it should be expected that the studied population, should to a reasonable extent, be representative of the exercise experiences of most PLLWHA. Thus, it affords us sufficient confidence to conclude that the estimate of evidence provided in these studies should approximate the real-life experiences of most of the PLWHA. Nevertheless, the inability to conduct meta-analyses for all the included studies that assessed for QoL due to limited reporting of outcome variables, should also be acknowledged as a limitation.

\section{Additional files}

Additional file 1: Search strategy in PubMed for immune function. The MESH terms used to search the Pubmed database for evidence of the impact of physical exercises on immune function in HIV conditions. (DOCX $15 \mathrm{~kb}$ )

Additional file 2: Search strategy in PubMed for Bone Mineral Density. The MESH terms used to search the Pubmed database for evidence of the impact of physical exercises on Bone Mineral Density in HIV conditions. (DOCX $15 \mathrm{~kb}$ )

Additional file 3: Search strategy in PubMed for Bone Mineral Density. The MESH terms used to search the Pubmed database for evidence of the impact of physical exercises on Quality of Life in HIV conditions. (DOCX $15 \mathrm{~kb}$ )

Additional file 4: The Cochrane Collaboration's tool for assessing the risk of bias (adapted from Table 8.5a in the Cochrane Handbook for Systematic Reviews of Interventions). The tool used for assessing the risk of bias in the selected studies from the database. (DOCX $35 \mathrm{~kb}$ )

Additional file 5: Quality of Evidence and Definitions (adapted from Guyatt et al., 2008). The weighing factors that define the quality of evidence for each of the selected studies. (DOCX $17 \mathrm{~kb}$ )

Additional file 6: PRISMA checklists for immune function. A diagrammatic flow of how the studies on the impact of exercise on immune function were selected from the database considering the stated eligibility criteria. (DOCX $43 \mathrm{~kb}$ )

Additional file 7: PRISMA checklists for Bone mineral density. A diagrammatic flow of how the studies on the impact of exercise Bone mineral density were selected from the database considering the stated eligibility criteria. (DOCX 39 kb) 
Additional file 8: PRISMA checklists for quality of life. A diagrammatic flow of how the studies on the impact of exercise quality of life were selected from the database considering the stated eligibility criteria. (DOCX $44 \mathrm{~kb})$

\begin{abstract}
Abbreviations
AIDS: Acquired immune deficiency syndrome; AMED: Allied and Complementary Medicine Database; ART: Highly Active Antiretroviral therapy; BFR: body fat redistribution; BMD: Bone mineral density; CINAHL: Cumulative Index to Nursing and Allied Health Literature; CON: Control; EMBASE: Excerpta Medica database; EQ-5D: Euro quality of life-5 dimensions; ES: Effect size; EXS: Exercise; GRADE: Grading of Recommendations Assessment Development and Evaluation; HIV: Human immune deficiency virus; HRR: Heart rate reserve; MeSH: Medical subject heading; MHR: Maximum heart rate; MOS: Medical Outcomes Study; NHREC: Nigeria Health Research Ethics Committee; NR: Not recorded; PEDro : Physiotherapy Evidence Database; PLWHA: People living with HIV/AIDS; PREG: progressive resistance exercise group; PRG: Progressive resistance exercise group; PRISMA: Preferred Reporting Items for Systematic Reviews and Meta-analyses; PROSPERO: International Prospective Register of Systematic Reviews; QoL: Quality of life; RCTS: Randomized control trials; RevMan: Review Manager; RM: Repetition maximum; ROB: Risk of bias; SF36: Short form MOS; SWD: Short wave diathermy; WHOQOL: World Health Organization Quality of Life; WHS: Women's Health Study
\end{abstract}

\section{Acknowledgments}

We wish to acknowledge all the authors whose works are cited in this study and likewise the College of Medicine library staff of the University of Nigeria, Enugu Campus, and the Hochschule Hannover University, Expo plaza 12, Hannover, Germany, for all their support, permission, assistance, and contributions to the success of this work.

\section{Funding}

This research received no specific grant from any funding agency in the public, commercial, or not-for-profit sectors.

\section{Availability of data and materials}

The datasets supporting the conclusions of this article are available in the institutional University of Nigeria repository and will be made easily available on request when required.

\section{Authors' contributions}

$\mathrm{SCl}$ and FOl conceived the study, participated in the literature search and review, data extraction, study design and coordination, performed the statistical analysis, and helped draft the manuscript. NII participated in data extraction and helped drafted the manuscript. FEE participated in literature search and review, data extraction and helped draft the manuscript. ADE, PCO, AON, SNE, GF and NRD participated in the design of the study, coordination, and helped draft the manuscript. All authors read and approved the final manuscript.

\section{Ethics approval and consent to participate}

This study involves data from already published works, hence, did not require ethical approval and certification.

\section{Consent for publication}

Not applicable.

\section{Competing interests}

The Authors declare that there is no conflict of interest.

\section{Publisher's Note}

Springer Nature remains neutral with regard to jurisdictional claims in published maps and institutional affiliations.

\section{Author details}

'Department of Medical Rehabilitation, Faculty of Health Sciences, University of Nigeria, Enugu Campus, Enugu, Nigeria. ${ }^{2}$ Department of Radiation Medicine, Faculty of Medical Sciences, College of Medicine, University of Nigeria, Ituku-Ozalla Campus, Enugu, Nigeria. ${ }^{3}$ Exercise Immunology/Palliative care unit, Department of Physiotherapy, University of Nigeria, Teaching
Hospital, Ituku/Ozalla, Enugu State, Nigeria. ${ }^{4}$ Clinical Trial Consortium University of Nigeria, Nsukka, Nigeria. ${ }^{5}$ Fakultaat III, Hochschhule Hannover University of Applied Sciences \& Arts, Expo Plaza 12, 30539 Hannover, Germany. ${ }^{6}$ Department of Physiotherapy, Faculty of Health Sciences, School of Therapeutic Studies, University of the Witwatersrand, 7 York Road, Parktown, 2193 Johannesburg, South Africa.

Received: 26 September 2017 Accepted: 18 March 2019

Published online: 24 April 2019

\section{References}

1. Poorolajal J, Hooshmand E, Mahjub H, Esmailnasab N. Survival rate of AIDS disease and mortality in HIV-infected patients: a meta-analysis. Public Health [Internet]. 2016 [cited 2017 Aug 13]; Available from: http://www. sciencedirect.com/science/article/pii/S0033350616300646

2. Neto M, Conceição C, Carvalho V, Brites C. Effects of combined aerobic and resistance exercise on exercise capacity, muscle strength and quality of life in HIV-infected patients: a systematic review and. PLoS One [Internet]. 2015 [cited 2017 Aug 13]; Available from: http://journals.plos.org/plosone/ article?id=10.1371/journal.pone.0138066

3. Garcia A, Fraga GGA, Vieira RC, Silva CMS, Trombeta JCDS, Navalta JW, et al. Effects of combined exercise training on immunological, physical and biochemical parameters in individuals with HIV/AIDS. 2014 May 9 [cited 2016 Nov 6];32(8):785-92. Available from: http://www. tandfonline.com/doi/ abs/10.1080/02640414.2013.858177

4. WHO | Number of deaths due to HIV. WHO [Internet]. 2016 [cited 2017 Aug 13]; Available from: http://www.who.int/gho/hiv/epidemic_status/deaths/en/.

5. Jaggers JR, Hand GA. Health Benefits of Exercise for People Living With HIV: A Review of the Literature. Am J Lifestyle Med [Internet]. 2014; 1559827614538750-. Available from: http://ajl.sagepub.com/content /early/ 2014/06/13/1559827614538750.

6. Negredo E, Bonjoch A, Puig J, Echeverría P, Estany C, Santos JR, et al. Longterm changes in bone mineral density after switching to a protease inhibitor monotherapy in HIV-infected subjects. New Microbiol. 2015;38(2):193-9.

7. Maffezzoni F, Porcelli T, Karamouzis I, Quiros-Roldan E, Castelli F, Mazziotti G, et al. Osteoporosis in human immunodeficiency virus patients - an emerging clinical concern. US Endocrinol [Internet]. 2014;10(1):84-8.

8. Cotter E, Mallon P, Doran P. Is PPAR a Prospective Player in HIV-1Associated Bone Disease? PPAR Res [Internet]. 2009 [cited 2017 Aug 13]; Available from: https://www.hindawi.com/journals/ppar/2009/421376/abs/

9. Fillipas S, Oldmeadow LB, Bailey MJ, Cherry CL. A six-month, supervised, aerobic and resistance exercise program improves self-efficacy in people with human immunodeficiency virus: a randomised controlled trial. Aust J Physiother. 2006;52(3):185-90.

10. Nixon S, Brien OK, Glazier R, Am T. Aerobic exercise interventions for adults living with HIV / AIDS ( review ). Cochrane Database Syst Rev. 2009;1.

11. O'Brien K, Tynan a-M, Nixon S, Glazier RH. Effects of progressive resistive exercise in adults living with HIV/AIDS: systematic review and meta-analysis of randomized trials. AIDS Care 2008;20(6):631-653.

12. Santos WR, Paes PP, Ferreira-Silva IA, Santos AP, Vercese N, Machado DRL, de Paula FJA, Donadi EA, Navarro AM, Fernandes APM. Impact of strength training on bone mineral density in patients infected with HIV exhibiting lipodystrophy. J Strength Cond Res. 2015;29(12):3466-71.

13. Maduagwu SM, Kaidal A, Gashau W, Balami A, Ojiakor AC, et al. Effect of aerobic exercise on CD4 cell count and lipid Profie of HIV infected persons in north eastern Nigeria. J AIDS Clin Res. 2015;6:508. https://doi.org/10.4172/ 2155-6113.1000508

14. Ezema Cl, Onwunali AA, Lamina S, Ezugwu UA, Amaeze AA, Nwankwo MJ. Effect of aerobic exercise training on cardiovascular parameters and CD4 cell count of people living with human immunodeficiency virus / acquired immune deficiency syndrome : A randomized controlled trial. 2014;17(5):543-8

15. Tiozzo E, Jayaweera D, Rodriguez A, Konefal J, Melillo AB, Adwan S, Chen L, Parvus C, Figueroa M, Hodgson N, Woolger JM, Kanka R, Perry A, Lewis JE. Short-term combined exercise training improves the health of HIV-infected patients. J AIDS HIV Res. 2013;5:80-9.

16. Zanetti HR, Cruz LG da, Lourenço CLM, Neves F de F, Silva-Vergara ML, Mendes EL. Non-linear resistance training reduces inflammatory biomarkers in persons living with HIV: A randomized controlled trial. Eur J Sport Sci [Internet]. 2016;16(8):1232-9. Available from: https://www.tandfonline.com/ doi/full/10.1080/17461391.2016.1167962 
17. Anandh V, Peter I, Alagesan J, Rajendran K. Effect of progressive resistance training on functional capacity, quality of life and CD4 count in people with HIV/AIDS. Int J Physiother Res [Internet]. 2014 [cited 2017 Sep 12]; Available from: http://oaji.net/articles/2014/287-1407760129.pdf

18. Higgins J, Green S. Cochrane Handbook for Systematic Reviews of Interventions Version 5.1. 0 [updated March 2011]. The Cochrane Collaboration, 2014. http://www.cochrane-handbook.org.

19. Akers J, Aguiar-Ibáñez R, Baba-Akbari Sari A. CRD's Guidance for Undertaking Reviews in Health care. York, UK: Centre for Reviews and Dissemination (CRD) 2009.

20. Microsoft. Microsoft Excel. Redmond, Washington: Microsoft, Computer Software 2013.

21. Cochrane Consumers and Communication Review Group. Communication review group: data extraction template for Cochrane reviews. Cochrane Collaboration 2007.

22. Guyatt GH, Oxman AD, Vist GE, Kunz R, Falck-Ytter Y, Alonso-Coello P, Schünemann HJ. Rating quality of evidence and strength of recommendations: GRADE: an emerging consensus on rating quality of evidence and strength of recommendations. BMJ: British Medical Journal. 2008 Apr 26;336(7650):924.

23. Baigis J, Korniewicz DM, Chase G, Butz A, Jacobson D, Wu AW. Effectiveness of a home-based exercise intervention for HIV-infected adults: a randomized trial. J Assoc Nurses AIDS Care. 2002;13(2):33-45.

24. Ogalha C, Luz E, Sampaio E, Souza R, Zarife A, Neto MG, Brites C. A randomized, clinical trial to evaluate the impact of regular physical activity on the quality of life, body morphology and metabolic parameters of patients with AIDS in Salvador, Brazil. JAIDS Journal of Acquired Immune Deficiency Syndromes. 2011;57:S179-85.

25. Perna FM, LaPerriere A, Klimas N, Ironson G, Perry A, Pavone J, Koppes L. Cardiopulmonary and CD4 cell changes in response to exercise training in early symptomatic HIV infection. Med Sci Sports Exerc. 1999;31(7):973-9.

26. Smith, B.A. et al. Aerobic Exercise : Effects on Parameters Related to Fatigue ,Dyspnea, Weight and Body Composition in HIV-Infected Adults. AIDS, 2001 15(6).

27. Stringer WW, Berezovskaya M, O'Brien WA, Beck CK, Casaburi R. The effect of exercise training on aerobic fitness, immune indices, and quality of life in HIV+ patients. Med Sci Sports Exerc. 1998;30:11-6.

28. Terry L, Sprinz E, Stein R, Medeiros NB, Oliveira J, Ribeiro JP. Exercise training in HIV-1-infected individuals with dyslipidemia and lipodystrophy. Med Sci Sports Exerc. 2006;38(3):411-7.

29. Terry L, Sprinz E, Ribeiro JP. Moderate and high intensity exercise training in HIV-1 seropositive individuals: a randomised trial. Int J Sports Med. 1999;20:142-6.

30. Yar'zever IS, Abubakar U, Toriola AL, lgbokwe NU. Effects of 12 weeks cycle exercise programme on CD4 count and viral load in HIV sero-positive patients in Kano, Nigeria. Journal of AIDS and HIV Research. 2013;5(11):415-21.

31. Farinatti PT, Borges JP, Gomes RD, Lima D, Fleck SJ. Effects of a supervised exercise program on the physical fitness and immunological function of HIV-infected patients. J Sports Med Phys Fitness. 2010 Dec 1;50(4):511.

32. Agin D, Gallagher D, Wang J, Heymsfield SB, Pierson RN Jr, Kotler DP. Effects of whey protein and resistance exercise on body cell mass, muscle strength, and quality of life in women with HIV. Aids. 2001;15(18):2431-40.

33. Gillespie, J. V. Health promotion and quality of life in HIV-1 infected individuals (doctoral dissertation, the Ohio State University). 1997.

34. Maharaj SS, Chetty V. Rehabilitation program for the quality of life for individuals on highly active antiretroviral therapy in KwaZulu-Natal, South Africa: a short report. Int J Rehabil Res. 2011:34(4):360-5.

35. Mkandla K, Myezwa H, Musenge E. The effects of progressive-resisted exercises on muscle strength and health-related quality of life in persons with HIVrelated poly-neuropathy in Zimbabwe. AIDS Care. 2016;28(5):639-43.

36. Galantino ML, Shepard K, Krafft L, Laperriere A, Ducette J, Sorbello A, Barnish M, Condoluci D, Farrar JT. The effect of group aerobic exercise and t'ai chi on functional outcomes and quality of life for persons living with acquired immunodeficiency syndrome. Journal of Alternative \& Complementary Medicine: Research on Paradigm, Practice, and Policy. 2005 Dec 1;11(6):1085-92.

37. Mutimura E, Stewart A, Crowther NJ, Yarasheski KE, Cade WT. The effects of exercise training on quality of life in HAART-treated HIV-positive Rwandan subjects with body fat redistribution. Qual Life Res. 2008 Apr 1;17(3):377.

38. Fairfield WP, Treat M, Rosenthal DI, Frontera W, Stanley T, Corcoran C, Costello M, Parlman K, Schoenfeld D, Klibanski A, Grinspoon S. Effects of testosterone and exercise on muscle leanness in eugonadal men with AIDS wasting. J Appl Physiol. 2001 Jun 1;90(6):2166-71.
39. Grinspoon S, Corcoran C, Parlman K, Costello M, Rosenthal D, Anderson E, Stanley T, Schoenfeld D, Burrows B, Hayden D, Basgoz N. Effects of testosterone and progressive resistance training in Eugonadal men with AIDS WastingA randomized. Controlled Trial Annals of Internal Medicine. 2000 Sep 5;133(5):348-55.

40. Neidig JL, Smith BA, Brashers DE. Aerobic exercise training for depressive symptom management in adults living with HIV infection. J Assoc Nurses AIDS Care. 2003;14(2):30-40.

41. Rojas R, Schlicht W, Hautzinger M. Effects of exercise training on quality of life, psychological well-being, immune status, and cardiopulmonary fitness in an HIV-1 positive population. Journal of Sport and Exercise Psychology. 2003 Dec;25(4):440-55

42. Souza PM, Jacob-Filho W, Santarém JM, Zomignan AA, Burattini MN. Effect of progressive resistance exercise on strength evolution of elderly patients living with HIV compared to healthy controls. Clinics. 2011;66(2):261-6.

43. O'Brien K, Nixon S, Tynan AM, Glazier R. Aerobic exercise interventions for adults living with HIV/AIDS. The Cochrane Library. 2010.

44. O'Brien KK, Tynan AM, Nixon SA, Glazier RH. Effectiveness of aerobic exercise for adults living with HIV: systematic review and meta-analysis using the Cochrane collaboration protocol. BMC Infect Dis. 2016;16(1):182.

45. Abaraogu, U.O et al., (2017). The Effect of Structured Patient Education on Physical Activity in Patient with Peripheral Arterial Disease and Intermittent Claudication: A Systematic Review, European Journal of Vascular and Endovascular Surgery. http://dx.doi.org/10.106/j.ejvs.2017.04.003.

46. Cochrane, T. C. Review Manager (RevMan) 5.3 Copenhagen: The Nordic Cochrane Centre. 2014.

47. Moher D, Liberati A, Tetzlaff J, et al. Preferred reporting items for systematic reviews and meta-analyses: the PRISMA statement. PLoS Med. 2009;6:e1000097.

48. Moher D, Shamseer L, Clarke M, et al. Preferred Reporting Items for Systematic Review and Meta-analysis protocols (PRISMA-P) 2015 statement. Syst Rev: 4:1.

49. Shamseer L, Moher D, Clarke M, et al. Preferred Reporting Items for Systematic Review and Meta-analysis Protocols (PRISMA-P): Elaboration and Explanation. BMJ 2015; 349:pg7647.

50. Ibeneme S, Uzoho A, Ibeneme G, Nna E. Effects of aerobic exercises on bone-specific alkaline phosphatase and pyridinoline as markers of bone turnover in women at post-.

51. Crystal S, Fleishman JA, Hays RD, Shapiro MF, Bozzette SA. Physical and role functioning among persons with HIV: results from a nationally representative survey. Medical care. 2000 Dec 1:1210-23. Menopause. Physiotherapy 2015; 101(supp. 1): e1564. S.

\section{Ready to submit your research? Choose BMC and benefit from:}

- fast, convenient online submission

- thorough peer review by experienced researchers in your field

- rapid publication on acceptance

- support for research data, including large and complex data types

- gold Open Access which fosters wider collaboration and increased citations

- maximum visibility for your research: over $100 \mathrm{M}$ website views per year

At BMC, research is always in progress.

Learn more biomedcentral.com/submissions 